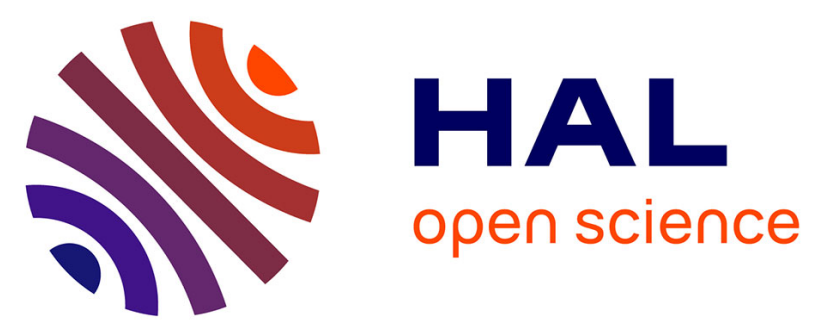

\title{
A Novel Strategy for the Detection and Quantification of Nanoplastics by Single Particle Inductively Coupled Plasma Mass Spectrometry (ICP-MS)
}

Javier Jiménez-Lamana, Lucile Marigliano, Joachim Allouche, Bruno Grassl, Joanna Szpunar, Stephanie Reynaud

\section{To cite this version:}

Javier Jiménez-Lamana, Lucile Marigliano, Joachim Allouche, Bruno Grassl, Joanna Szpunar, et al.. A Novel Strategy for the Detection and Quantification of Nanoplastics by Single Particle Inductively Coupled Plasma Mass Spectrometry (ICP-MS). Analytical Chemistry, 2020, 92 (17), pp.11664-11672. 10.1021/acs.analchem.0c01536 . hal-02977866

\section{HAL Id: hal-02977866 https://hal-univ-pau.archives-ouvertes.fr/hal-02977866}

Submitted on 6 Jan 2021

HAL is a multi-disciplinary open access archive for the deposit and dissemination of scientific research documents, whether they are published or not. The documents may come from teaching and research institutions in France or abroad, or from public or private research centers.
L'archive ouverte pluridisciplinaire HAL, est destinée au dépôt et à la diffusion de documents scientifiques de niveau recherche, publiés ou non, émanant des établissements d'enseignement et de recherche français ou étrangers, des laboratoires publics ou privés. 


\title{
A novel strategy for the detection and quantification of nanoplastics by single particle inductively coupled plasma mass spectrometry (ICP-MS)
}

\author{
Javier Jiménez-Lamana*, Lucile Marigliano, Joachim Allouche, Bruno Grassl, Joanna Szpunar and Sté- \\ phanie Reynaud
}

Universite de Pau et des Pays de l'Adour, E2S UPPA, CNRS, Institute of Analytical and Physical Chemistry for the Environment and Materials (IPREM), Pau, France

\section{Corresponding author}

*E-mail: Phone: +33540175037

\begin{abstract}
A method for the detection and quantification of nanoplastics (NPTs) at environmentally relevant concentrations was developed. It is based on conjugating nanoplastics with functionalized metal (Au)-containing nanoparticles (NPs), thus making them detectable by highly sensitive inductively coupled plasma mass spectrometry (ICP-MS) operated in single particle (SP) mode. The selectivity of the method was achieved by the coupling of negatively charged carboxylate groups present at the surface of nanoplastics with a positively charged gelatin attached to the custom-synthesized AuNPs. The adsorbed Au produced a SP-ICP-MS signal allowing the counting of individual nanoplastic particles, and hence their accurate quantification $(<5 \%$ error). Polystyrene (PS) particle models with controlled surface functionalization mimicking the nanoplastics formed during natural degradation of plastic debris were used for the method development. The nanoplastic number concentration quantification limit was calculated at $8.4 \times 10^{5} \mathrm{NPTs} \mathrm{L}^{-1}$ and the calibration graph was linear up to $3.5 \times 10^{8} \mathrm{NPTs} \mathrm{L}^{-1}$. The method was applied to the analysis of nanoplastics of up to $1 \mu \mathrm{m}$ in drinking, tap and river water. The minimum detectable and quantifiable size depended on the degree of functionalization and the surface available for labeling. For a fully functionalized nanoplastic, the lower size detectable by this strategy is reported as $135 \mathrm{~nm}$. In this study, authors use the recommendation for the definition of nanoplastics as plastic particles with sizes ranging between $1 \mathrm{~nm}$ and $1 \mu \mathrm{m}$, although it has not been accepted by a dedicated organization.
\end{abstract}

\section{INTRODUCTION}

The increasing amount of plastic waste in the marine environment has become a major cause of concern among scientists' community, policy-makers and public opinion ${ }^{1}$. Indeed, millions of tons of plastics end up in the oceans where they undergo fragmentation, mostly due to solar radiation, mechanical forces and biological action leading to smaller debris ${ }^{2-4}$. Microplastics (plastic particles below $5 \mu \mathrm{m}$ ) have been studied in marine and freshwater systems for a number of years. ${ }^{5}$ Recently, there has been a surge of interest in the presence and fate of even smaller, sub- $\mu \mathrm{m}$ plastic particles. Such particles have been termed "nanoplastics", 6,7 referring to plastic particles having colloidal behavior and ranging between $1 \mathrm{~nm}$ and $1 \mu \mathrm{m} .{ }^{8}$ It has to be said, however, that this trend in terminology is raising controversy, mainly because of the lack of coherence with the ISO definition of the term "nano" which requires that at least one dimension of a particle be $100 \mathrm{~nm}$.

Although it has been suggested that nanoplastics are potentially more hazardous than microplastics ${ }^{9,10}$, very little is known about the presence of these emerging contaminants. Besides the fact that nanoplastics can potentially enter higher organisms, their presence in the water column may affect planktonic species, and disrupt the energy flow in marine ecosystems ${ }^{11}$. In addition, due to their high surface area to volume ratio, nanoplastics are expected to be able to adsorb, concentrate and act as vector of toxic pollutants. Information on the presence of plastic particles in the nanometer size range in the environment is very scarce. Such particles have been detected in the north Atlantic gyre only recently. ${ }^{12}$

The European Commission has recognized the lack of quantitative analytical methods in order to obtain realistic risk assessment studies of nanoplastics ${ }^{13}$. Because of their small size and consisting mainly of carbon, they elude most of the instrumental techniques available. Therefore, new analytical techniques have to be developed to provide information about the abundance, size distribution and/or chemical composition of nanoplastics at low concentrations and particle size detection limits ${ }^{14,15}$.

Some techniques usually dedicated to nanomaterials characterization have been employed for the investigation of nanoplastics. They include optical methods such as, e.g., nanoparticle tracking analysis (NTA) ${ }^{16,17}$, scanning electron microscopy $(\mathrm{SEM})^{18,19}$, transmission electron microscopy $(\mathrm{TEM})^{20}$, SEM coupled with energy dispersive X-ray spectroscopy (SEMEDX), ${ }^{21}$ and fluorescence microscopy ${ }^{22,23}$. On the other hand, some authors recently proposed asymmetrical flow field flow fractionation (AF4) coupled to multi-angle light scattering (MALS) in order to detect and characterize nanoplastics in a polydisperse nanoplastic sample ${ }^{24}$, in a food matrix ${ }^{25}$, and in spiked eggfishs ${ }^{26}$. However, these techniques have important drawbacks: they might under- or overestimate abundance, be 
tedious and time consuming, and can perturb the physiochemical state of the sample ${ }^{27}$. AF4-MALS may be a powerful tool to obtain particle size distribution, but its sensitivity is too low to match environmentally relevant concentrations of nanoplastics. Besides, the above mentioned techniques require an additional sample preparation step, due to the necessity of sample preconcentration.

Mass spectrometry based techniques have also been proposed for the analysis of nanoplastics ${ }^{15}$. For instance, the use of pyrolysis coupled to gas chromatography-mass spectrometry (Py-GC-MS) was reported for the detection and identification of nanoplastics in aqueous media ${ }^{12,28}$. The use of a preconcentration step allowed an improvement of the limit of detection of the technique $\left(20 \mu \mathrm{g} \mathrm{L}^{-1}\right)$. Py-GC-MS was shown to be a good alternative to Fourier transform infrared (FTIR) or Raman spectroscopy, which are commonly used to provide the chemical identity of particles ${ }^{28}$. The mass quantification of nanoplastics by Py-GC-MS was investigated upon preconcentration by cloud-point extraction combined with thermal degradation ${ }^{29}$. Nevertheless, Py-GC-MS still needs to be investigated for quantitative purposes due to the lack of reproducibility $^{30}$. On the other hand, novel approaches based on thermal fragmentation and matrix-assisted laser desorption/ionization time-of-flight mass spectrometry (MALDITOF MS) ${ }^{31}$, and liquid chromatography coupled to high resolution mass spectrometry (LC-HRMS) with an atmospheric pressure photoionization source (APPI) ${ }^{32}$ were recently proposed for the mass quantification of nanoplastics and small microplastics. None of these techniques, however, is suitable for the quantification of nanoplastics (number concentration) at environmentally relevant concentrations.

On the other hand, polystyrene (PS), reported in literature l3,34 $^{33}$ as a major plastic debris occurring in the environment, was chosen as a model for the method development. As commercially available polystyrene latex (PSLs) particles contain additives, they were considered not to be representative models because of the scarcity of knowledge of their chemical composition and surface functionalisation. ${ }^{35}$ Therefore, soap and metal-free model PS nanoplastics with controlled functionality and purity were chosen for the analytical developments. More specifically, PS particles functionalized with carboxyl groups at the surface were synthesized, mimicking aged nanoplastics. It has been shown that the surface of polymer nanoparticles in the environment present carbonyl groups $^{35}$, because of oxidation processes. As result, environmental nanoplastics presenting oxidized surfaces may act as carriers of other pollutants, such as, e.g., heavy metals.

The objective of this work was to develop a novel analytical strategy based on the conjugation of the carboxylate groups present at the surface of nanoplastics with metal-containing functionalized probes in order to make them detectable and quantifiable in aqueous media by single particle inductively coupled plasma mass spectrometry (SP-ICP-MS). This technique, working on a particle-by-particle basis, is able to detect metal-containing nanoparticles with the highest sensitivity, achieving limits of detection down to attograms ${ }^{36}$. In order to make nanoplastics detectable, the surface carboxylate groups formed during plastics oxidation leading to the formation of nanoplastics were conjugated with custom-designed goldlabelled amine functionalized nanoparticles, so that the conjugates could be detected and counted as ${ }^{197} \mathrm{Au}$ by ICP-MS with very high sensitivity.

\section{EXPERIMENTAL SECTION}

Reagents and chemicals. Gold (III) chloride hydrate $\left(\mathrm{HAuCl}_{4}\right)$, trisodium citrate dihydrate $\left(\mathrm{Na}_{3}\right.$-citrate $)$ and gelatin Type A 300 bloom, isoelectric point IEP $\approx 8$ ) from porcine skin were purchased from Sigma-Aldrich (Saint Quentin Fallavier, France). Commercial gold nanoparticle suspensions (AuNPs) with nominal sizes of $50 \pm 3$ and $80 \pm 4 \mathrm{~nm}$ were obtained from BBI solutions (Crumlin, UK). A standard solution of $1000 \mathrm{mg} \mathrm{L}^{-1}$ gold was purchased from Plasma CAL standards (Teddington, UK). Commercial carboxylated polystyrene particle suspensions (PSL) with nominal diameters of $759 \pm 23,990 \pm 20$ and $3030 \pm 121 \mathrm{~nm}$ were purchased from Polysciences (Warrington, PA). All of them present zeta potential values between -47 and $-50 \mathrm{mV}$ at $\mathrm{pH} 7$.

Synthesis of gold nanoparticles. Gelatin coated AuNPs (AuNPs@gel) with a median size of $17 \pm 3 \mathrm{~nm}$ were synthesized as follows: monodisperse AuNPs were first elaborated by rapidly injecting $\mathrm{Na}_{3}$-citrate $\left(11.4 \mathrm{~g} \mathrm{~L}^{-1}, 0.3 \mathrm{~mL}\right)$ into a boiling aqueous solution of $\mathrm{HAuCl}_{4}\left(0.1 \mathrm{~g} \mathrm{~L}^{-1}, 20 \mathrm{~mL}\right)$ under stirring. Then, a gelatin coating on AuNPs was achieved by injecting drop by drop the previous solution at $40^{\circ} \mathrm{C}$ into $3 \mathrm{~mL}$ of gelatin solution $\left(0.3 \mathrm{~g} \mathrm{~L}^{-1}\right)$. The size distribution is shown in the supporting information (Figure S-1).

Synthesis of polystyrene (PS) nanoplastic models. PS nanoplastics were synthesized avoiding any additives, especially surfactants, bactericide species and trace metals potentially present in commercial standards. The synthesis and characteristics of soap-free polystyrene models were detailed elsewhere $^{37}$. A suspension of spherical particles (PS22) with surface functionalized by carboxylic groups was used throughout this study. It presents a number average diameter of $420 \pm 20$ $\mathrm{nm}$ (determined by scanning electron microscopy), a low polydispersity (polydispersity index (PDI) of 0.009), zeta potential of $-46 \mathrm{mV}$ at $\mathrm{pH} \mathrm{7,} \mathrm{particle} \mathrm{surface} \mathrm{functionality} \mathrm{of}$ $45 \mathrm{COOH}$ groups per $\mathrm{nm}^{2}$.

\section{Instrumentation}

Single Particle ICP-MS. An Agilent 7900 ICP-MS (Agilent, Tokyo, Japan) equipped with Single Nanoparticle Application Module was used for the detection and quantification of nanoplastics by monitoring the Au signal. The default instrumental and acquisition parameters are listed in Table 1.

The calculation of transport efficiency affects critically the accuracy of in SP-ICP-MS results. The two methods mostly used in literature to calculate transport efficiency are the particle frequency method and particle size method ${ }^{38}$. Transport efficiency was calculated according to both methods using a 50-nm AuNPs suspension as calibration material. The transport efficiency calculated by the particle frequency method was used to determine the nanoplastic number concentration, whereas the transport efficiency calculated by the particle size method was used to determine the mass of Au per nanoplastic particle. The sample flow rate was calculated daily by measuring the mass of water taken up by the peristaltic pump during $2 \mathrm{~min}$. This operation was repeated twice and the average values were used for calculations. After each sample analysis, the software automatically processed the raw data and generated the particle concentration and the signal frequency histogram. The latter was converted into mass distribution through equation 1 that relates signal and mass:

$$
m_{p}=I_{p} \times \frac{1}{K} \times t_{d} \times q \times \eta_{n}
$$


where $m_{p}$ is the mass of Au per nanoplastic, $I_{p}$ the Au signal in counts, $t_{d}$ the dwell time, $q$ the sample uptake flow, $\eta_{n}$ the transport efficiency and $K$ the response of the instrument per $\mathrm{ppb}$ of $\mathrm{Au}$. Time scans and mass distributions were prepared in Origin 8.5 software (Northampton, MA).

Scanning electron microscopy (SEM). Images were obtained using a JEOL JAMP-9500F Field Emission Auger Microprobe operated at $30 \mathrm{kV}$ and $5 \mathrm{nA}$. The powders were deposited on an aluminum foil and placed in an oven at $120{ }^{\circ} \mathrm{C}$ for $5 \mathrm{~min}$ before being mounted on the sample microscope holder.

Procedure. The analytical strategy developed in this work is based on the conjugation of carboxylated PS nanoplastics with gelatin coated AuNPs. To prepare the suspension of conjugated (PS22 or PSL) nanoplastics, an aliquot of $20 \mu \mathrm{L}$ of AuNPs@gel suspension was mixed with $20 \mu \mathrm{L}$ of a suspension of nanoplastics at a ratio of approx. 500:1 in terms of number of particles. The resulting mixture was diluted accordingly with water in order to have a nanoplastic number concentration of around $1 \times 10^{8} \mathrm{~L}^{-1}$ or lower prior to SP-ICP-MS analysis.

Table 1. Default instrumental and data acquisition parameters for SP-ICP-MS

\begin{tabular}{ll}
\hline $\begin{array}{l}\text { Instrumental parameters } \\
\text { RF power }\end{array}$ & $1550 \mathrm{~W}$ \\
Argon gas flow rate & \\
$\quad$ Plasma & $15 \mathrm{~L} \mathrm{~min}^{-1}$ \\
$\quad$ Auxiliary & $0.9 \mathrm{~L} \mathrm{~min}^{-1}$ \\
$\quad$ Nebulizer & $1.10 \mathrm{~L} \mathrm{~min}^{-1}$ \\
Sample uptake rate & $0.300 \mathrm{~mL} \mathrm{~min}^{-1}$ \\
& \\
Data acquisition parameters & \\
Dwell time & $100 \mu \mathrm{s}$ \\
Readings per replicate & 600000 \\
Total acquisition time & $60 \mathrm{~s}$ \\
Isotope monitored & $197 \mathrm{Au}$ \\
\hline
\end{tabular}

Water samples. Drinking water of high hardness $(72 \mathrm{mg} \mathrm{Ca}$ $\mathrm{L}^{-1}, 19 \mathrm{mg} \mathrm{Mg} \mathrm{L}^{-1}$ ) was purchased from a local market. Tap water was collected from the municipal water system of Pau, France. River water was collected from Besòs River in Catalonia, Spain, in polypropylene conical bottom tubes of $250 \mathrm{ml}$ capacity, previously washed with nitric acid (2\%), rinsed thoroughly with water, and kept at $2 \sim 4{ }^{\circ} \mathrm{C}$ until the moment of their analysis. River sample was filtered through $5.0 \mu \mathrm{m}$ syringe filter before analysis.

\section{RESULTS AND DISCUSSION}

In a first approach, the labelling through interactions between $\mathrm{COO}^{-}$groups and positive metal ions was attempted. However, the total amount of metal adsorbed on each nanoplastic particle turned out to be insufficient for the correct quantification. Consequently, an alternative approach was proposed using positively-charged gelatin-coated gold nanoparticles (AuNPs@gel) as adsorbed tags of nanoplastic particles to make them detectable by ICP-MS. Type A gelatin is a protein composed of a set of amino acids, containing $\mathrm{NH}_{2}$ and $\mathrm{COOH}$ groups. Due to the protonation state of acid (carboxylates) and basic (amines) functions, gelatin provides a net global positive charge (isoelectric point $\approx 8$ ) at the working $\mathrm{pH}(6-8)^{39}$. Therefore, the labelling is achieved through electrostatic interactions between the global negative charge bearing by the deprotonated carboxylate groups from the surface of nanoplastics, and the positive charge of gelatin-coated gold nanoparticles at neutral $\mathrm{pH}$. In this way, an increase in the total mass of metal adsorbed per nanoplastic particle was achieved in comparison with the use of the ionic metal form.

Detection of AuNPs-labelled nanoplastics. A suspension of carboxylated model nanoplastics, PS22, was mixed with a suspension of AuNPs@gel and the resulting suspension of conjugate nanoplastic-AuNPs@gel was analyzed, without further dilution, by SEM. Images in Figure 1 confirmed the successful labelling of nanoplastics by a significant number of AuNPs@gel (white dots) covering the surface of PS22 nanoplastics. Low magnification images (figures 1a and 1b) show several nanoplastics with a good homogeneous gold coverage. In addition, high magnification pictures in figures $1 \mathrm{c}$ and $1 \mathrm{~d}$ display clearly gold nanoparticles adsorbed on a representative single polymer particle. The gold nanoparticles size was estimated on the basis of such images around $15 \pm 5 \mathrm{~nm}$ which is in good agreement with the size distribution obtained by SPICP-MS in Figure S-1.

The same suspension was diluted and analyzed by means of SP-ICP-MS. The time scan obtained by monitoring the ${ }^{197} \mathrm{Au}$ signal showed a significant number of pulses above the background (Figure 2a), produced by the ions coming from all the AuNPs@gel attached to a single nanoplastic. In addition, a background signal produced by AuNPs@gel that are not linked to any nanoplastic carriers and hence remain 'free' in the suspension is also observed. Since the concentration of 'free'AuNPs@gel is relatively high, each droplet introduce into the plasma will contain more than one nanoparticle, resulting in a steady background signal instead of individual peaks. The size of AuNPs@gel is also a critical parameter to be taken into account. The use of bigger AuNPs@gel will result in a higher $\mathrm{Au}$ mass per nanoparticle but also in a higher background due to nanoparticles not conjugated with nanoplastics that will produce a higher background that may hinder the detection of signals produced by conjugated nanoplastics. On the other hand, the use of smaller AuNPs@gel will produce a lower background, but also a lower signal of conjugated nanoplastics due to the presence of lower Au mass at the surface. The choice of AuNPs@gel of around $17 \mathrm{~nm}$ resulted in a good compromise between both factors. The removal of 'free'AuNPs@gel may sound attractive. It would lead to a time scan where signals observed are due to conjugates nanoplastics-AuNPs@gel only and hence to avoid a risk of false positives. In the developed methodology, the use of $17 \mathrm{~nm}$ AuNPs@gel allowed to obtain well-separated signals, without a previous separation step, making the occurrence of false positives negligible and thus allowing the quantification of nanoplastics. 


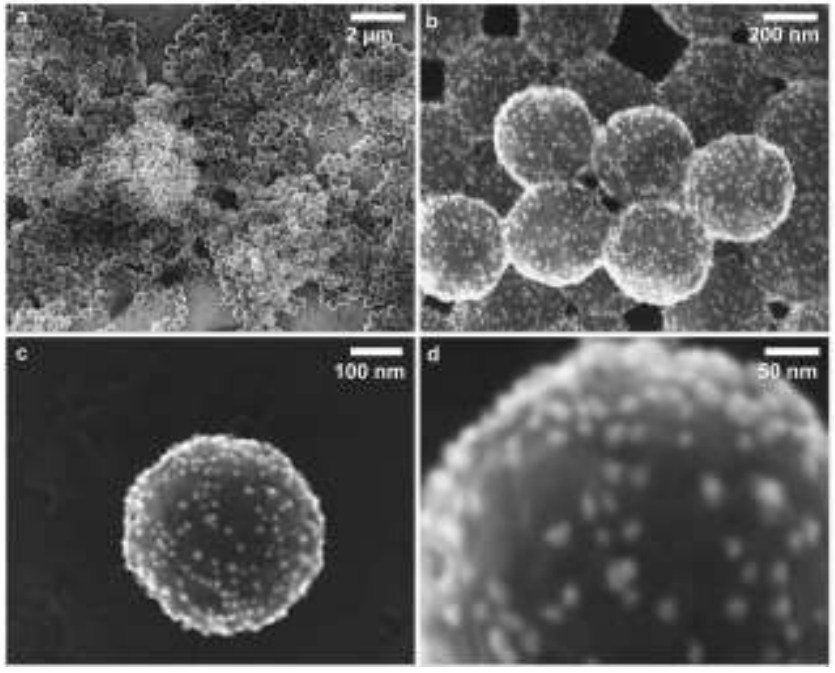

Figure 1. SEM images of several (a and b) and single (c and d) PS22 nanoplastics labelled with AuNPs@gel

The difference between the signals produced by not linked AuNPs@gel and by conjugated nanoplastics is perfectly reflected when zooming into the time scan obtained (Figure 2b). In order to confirm this difference, a method blank, consisting of a suspension of AuNPs@gel at the same nanoparticle concentration as in the previous mixture $\left(\sim 3 \times 10^{10} \mathrm{~L}^{-1}\right)$ but without the addition of nanoplastics, was analyzed by SP-ICP-MS. A zoom into the time scan showed the presence of a background signal coming from the AuNPs@gel (Figure 2c), whereas no peaks above the baseline were registered. This confirmed that the peaks observed in Figure 1a corresponded exclusively to nanoplastics conjugated with AuNPs@gel and not to an artefact. In this context, the possible occurrence of big aggregates of AuNPs@gel was investigated. These aggregates could produce signals leading to false positives. Figure $2 \mathrm{c}$ shows that in the time scan obtained for a suspension of AuNPs@gel, no signals due to agglomerates were observed. In addition, the UV-Vis spectrum of the AuNPs@gel suspension (Fig S-1 b) shows only one single maximum (near 500 $\mathrm{nm}$ ) corresponding to the typical plasmon resonance wavelength value of near $20-\mathrm{nm}$ gold nanoparticles. Such spectrum is characteristic for well dispersed gold nanoparticles without aggregates. $^{40}$ It is also important to highlight that the background signal obtained for the sample of conjugated nanoplastics is 3 times lower than that obtained for the blank of AuNPs@gel even though the nanoparticle concentration is the same for both suspensions. This can be explained by the fact than in the sample containing conjugated model nanoplastics a significant number of AuNPs@gel is attached to the polymer nanoparticles, and hence the concentration of free AuNPs@gel is lower than in the blank sample.

Finally, the possibility of destabilization of the conjugate nanoplastic-AuNPs@gel by depletion forces due to the high size relation between both particles must be discussed. The aggregation of conjugates would lead to a scenario where some nanoplastics will eventually settle down at the bottom of the suspension and other aggregates will be counted by SPICP-MS as single nanoplastics, resulting hence in an underestimation of the nanoplastic number concentration. In the proposed approach, the probability of this scenario is negligible due to the preparation of very dilute suspensions, which limits the physical contact between conjugates, and the analysis carried out immediately upon mixing. No agglomerates were observed in the next hour following the preparation of the conjugates.
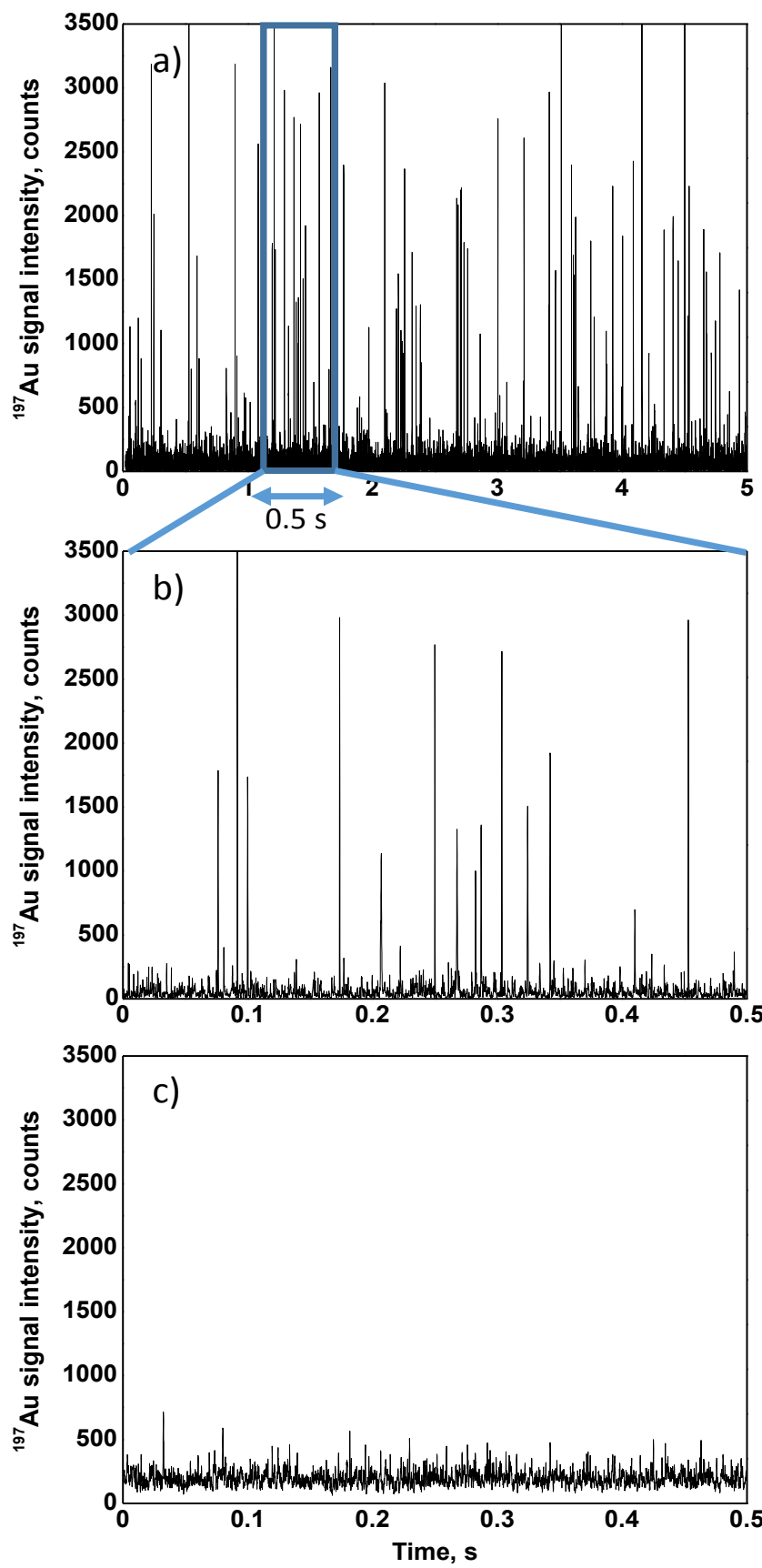

Figure 2. Time scan obtained by SP-ICP-MS for: a) a suspension of functionalized PS22 model nanoplastics conjugated with AuNPs@gel, with a zoom on b); and c) a suspensions of AuNPs@gel at the same concentration

Determination of transport efficiency. Two different methods used to calculate the transport efficiency were compared by analyzing two commercial AuNPs suspensions of different size, 50 and $80 \mathrm{~nm}$.

Transports efficiencies values obtained for both suspensions were in good agreement for each method (3.8 and $3.7 \%$ for particle frequency method and 6.9 and $7.1 \%$ for particle size method) but a significant difference between the methods was 
obtained (Table 2). This difference raised the question of which value should be used for the rest of the study. In order to answer this question, the following experiment was performed: one of the AuNPs suspension was used as reference material to calculate the transport efficiency by both methods, while the other AuNPs suspension was used as an 'unknown sample' and vice versa. The experimental values of nanoparticle number concentration and median diameter for the 'unknown sample' were calculated and compared with the theoretical ones. Results are shown in Table 2.

According to the results obtained, an accurate quantification of nanoparticle number concentration was obtained for both AuNPs suspensions when using the transport efficiency calculated by the particle frequency method, while the particle size method provided errors higher than $40 \%$. However, the median diameters calculated using the transport efficiency obtained by the particle frequency method were far from the nominal ones, while the particle size method reported accurate diameters. Similar results have been previously reported by other authors ${ }^{41}$. Liu et al investigated both transport efficiency calibration methods by using a NIST reference material (RM 8013), coming to the conclusion that the particle size method is more robust and yields accurate results ${ }^{42}$. However, the transport efficiency value calculated by the particle frequency in this study $(3.7-3.8 \%)$ is in very good agreement with the values (between 3.5 and $4 \%$ ) calculated by using the same NIST reference material in previous studies with the same ICP-MS instrument and sample introduction system ${ }^{43,44}$. Consequently, throughout the whole study, the transport efficiency calculated by the particle frequency was used in order to determine the nanoplastic number concentration. On the other hand, since according to the SP-ICP-MS theory size and mass are directly related ${ }^{36}$, the transport efficiency calculated by the particle size method was used to calculate the mass of Au per nanoparticle. Images and size distribution obtained by SEM for the 50-nm AuNPs suspension are shown in Supporting Information (Fig S-2).

Mass distribution and nanoplastic quantification. Once the transport efficiency determined, the time scans obtained for a suspension of nanoplastics conjugated with AuNPs@gel can be converted into signal frequency histogram and this into mass frequency histogram according to equation 1. As expected, the mass frequency histogram obtained for the suspension of conjugated PS22 model nanoplastics showed two distributions, the first one due to the AuNPs@gel that have not interacted with nanoplastics and the second one due to the AuNPs@gel linked to the surface of the nanoplastics (Figure 3 ), reflecting the two different types of signals recorded in a time scan (Figure 2b). Note that the Au mass distribution shown in Figure 3 was obtained without taking into account the threshold applied for the quantification of nanoplastics discussed below.

Table 2. Comparison of median sizes and nanoparticle number concentration values obtained by particle frequency and particle size methods for 50 and $80 \mathrm{~nm}$ AuNPs suspensions (mean \pm standard deviation; $\mathbf{n}=3$ )

\begin{tabular}{|c|c|c|c|c|}
\hline Calibration Material & \multicolumn{2}{|l|}{ AuNPs $50 \mathrm{~nm}$} & \multicolumn{2}{|l|}{ AuNPs $80 \mathrm{~nm}$} \\
\hline Method & Particle frequency & Particle size & Particle frequency & Particle size \\
\hline Transport efficiency, $\%$ & 3.8 & 6.9 & 3.7 & 7.1 \\
\hline Sample & \multicolumn{2}{|c|}{ AuNPs $80 \mathrm{~nm} ; 8.69 \times 10^{7} \mathrm{NPs} \mathrm{L}^{-1}$} & \multicolumn{2}{|c|}{ AuNPs $50 \mathrm{~nm} ; 9.32 \times 10^{7} \mathrm{NPs} \mathrm{L}^{-1}$} \\
\hline Nanoparticle concentration, NPs L ${ }^{-1}$ & $8.46 \pm 0.04 \times 10^{7}$ & $4.66 \pm 0.02 \times 10^{7}$ & $1.00 \pm 0.02 \times 10^{8}$ & $5.23 \pm 0.11 \times 10^{7}$ \\
\hline
\end{tabular}


$\mathrm{pH}$ plays a key role in the stability of the conjugate nanoplastics-AuNPs@gel. In order to investigate the $\mathrm{pH}$ working range, different suspensions of conjugated PS22 model nanoplastics were prepared at different $\mathrm{pH}$ and analyzed by SPICP-MS. No differences were found from $\mathrm{pH} 5.0$ to $\mathrm{pH} \mathrm{8.6,}$ showing that the conjugate was stable in that $\mathrm{pH}$ range, whereas a loss on the number of AuNPs@gel at the nanoplastics surface was observed at $\mathrm{pH}>8.6$.

Nanoplastic number concentration: linearity, limit of quantification and precision. Linearity was studied by preparing a series of suspensions of PS22 model nanoplastics conjugated with AuNPs@gel at different nanoplastic number concentrations and counting the number of peaks produced by SP-ICP-MS. The number of peaks detected was plotted against the nanoplastic number concentration (Figure 4). The calibration curve showed a good linear relationship from concentrations of $3.6 \times 10^{7} \mathrm{NPTs} \mathrm{L}^{-1}$ up to $3.3 \times 10^{8} \mathrm{NPTs} \mathrm{L}^{-1}$ with a slope of $1.19 \pm 0.02 \times 10^{-5}$ NPTs $\mathrm{L}^{-1}$.

The nanoplastic number concentration limit of quantification $\left(\mathrm{LOQ}_{\mathrm{NPT}}\right)$ can be related with the capability of counting 10 peaks generated by nanoplastics conjugated with AuNPs@gel in a situation of two well resolved populations. Under these conditions and by taking into account the slope of the calibration curve obtained in Figure 4, a nanoplastic number concentration quantification limit of $8.4 \times 10^{5} \mathrm{NPTs} \mathrm{L}^{-1}$ was obtained. On the other hand, the linearity of the calibration is lost for nanoplastic concentration above $3.5-4 \times 10^{8} \mathrm{NPTs} \mathrm{L}^{-1}$, as it can be seen in Figure S-3. This is explained by an underestimation on the number of peaks detected due to the counting of peaks generated by two nanoplastic as if they were individual nanoplastics.

The intra-assay precision of the nanoplastic number concentration determination was studied by analyzing each point of the calibration curve by triplicate. Relative standard deviations of 1-1.5\% were obtained for those nanoplastic concentrations implying the counting of 1000 or more peaks, whereas a value of $7 \%$ was obtained for the lowest concentration, which implied counting 400 peaks.

Lower and upper size limits of detection. In order to study the size limits of detections (upper and lower) of the strategy presented in this work, three commercial carboxylated polystyrene latex particle suspensions (PSL) with different nominal diameters (759, 990 and $3030 \mathrm{~nm}$ ) were conjugated with AuNPs@gel and analyzed by SP-ICP-MS.

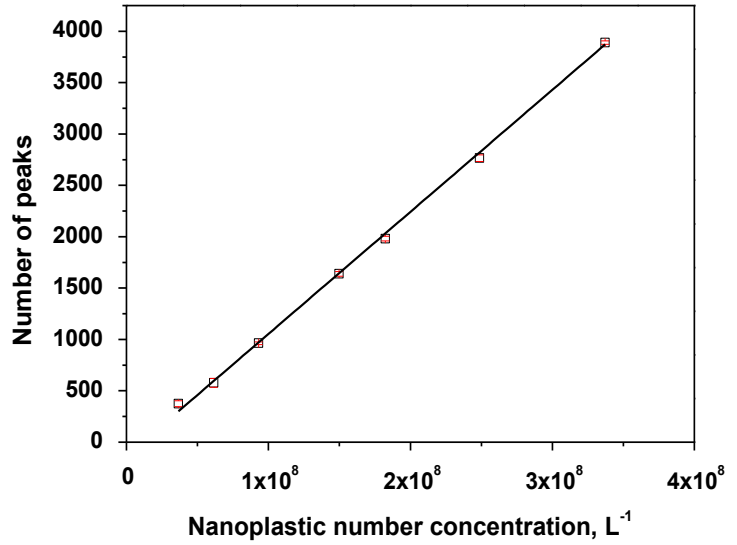

Figure 4. Linear relationship between nanoplastic number concentration and number of peaks counted by SP-ICP-MS. Errors bars in red $(n=3)$.

For the three standards tested, time scans with a significant number of peaks above the background baseline were obtained (Figure S-4). As it was explained before, in order to have an accurate quantification, the signals distribution generated by conjugated nanoplastic must be well resolved from the signal distribution generated by the background.

Well resolved distributions were obtained for the PSL particle suspensions of 759 and $990 \mathrm{~nm}$. As it can be seen in Figure S4 , the intensity of the peaks is increasing when increasing the size of the polymer particles. This is explained by the fact that the bigger the nanoplastic particle, the higher surface area is available for the conjugation with AuNPs@gel, which results in a higher mass of $\mathrm{Au}$ per nanoplastic. Under these conditions, accurate quantification in terms of the nanoplastic number concentration was obtained for both PSL particle suspensions (Table 3). The errors were of 1 and 5\% for the suspensions of 759 and $990 \mathrm{~nm}$, respectively.

However, the number concentration obtained for the PSL particle suspension of $3030 \mathrm{~nm}$ was 10 times lower than expected despite the fact that the signal distribution due to conjugated nanoplastics was well resolved from the distribution due to the background (Table 3). This fact may be explained by an insufficient vaporization and ionization of the nanoplastics in the plasma due to their size, resulting in a loss during the SP-ICP-MS analyses.

Table 3. Nanoplastic number concentration, Au mass per nanoplastic and number of AuNPs@gel per nanoplastic obtained by SP-ICP-MS for different carboxylated PS nanoplastics (mean \pm standard deviation; $\mathbf{n}=3$ )

\begin{tabular}{lllllll}
\hline Nanoplastic & Size, $\mathrm{nm}$ & $\begin{array}{l}\text { Theoretical concen- } \\
\text { tration, NPTs L }\end{array}$ & $\begin{array}{l}\text { Experimental } \\
\text { concentration, } \\
\text { NPTs L }^{-1}\end{array}$ & $\begin{array}{l}\text { Average Au mass } \\
\text { per NPT, fg }\end{array}$ & $\begin{array}{l}\text { Average number of } \\
\text { AuNPs@gel per } \\
\text { NPT }\end{array}$ & $\begin{array}{l}\text { Average num- } \\
\text { ber of } \\
\text { AuNPs@ gel per } \\
\mu m^{2}\end{array}$ \\
\hline PS22 & $420 \pm 20$ & $6.42 \times 10^{7}$ & $6.25 \pm 0.36 \times 10^{7}$ & $14.4 \pm 1.4$ & $290 \pm 28$ & $523 \pm 51$ \\
PSL & $759 \pm 23$ & $6.08 \times 10^{7}$ & $6.00 \pm 0.35 \times 10^{7}$ & $18.2 \pm 0.7$ & $365 \pm 14$ & $202 \pm 8$
\end{tabular}




\begin{tabular}{|c|c|c|c|c|c|c|c|}
\hline PSL & $990 \pm 20$ & $5.20 \times 10^{7}$ & $4.89 \pm 0.39 \times 10^{7}$ & $23.9 \pm 5.1$ & \multicolumn{2}{|c|}{$480 \pm 102$} & $156 \pm 33$ \\
\hline PSL & $3030 \pm 121$ & $5.18 \times 10^{8}$ & $2.81 \pm 0.92 \times 10^{7}$ & $50.2 \pm 4.0$ & \multicolumn{2}{|c|}{$1008 \pm 80$} & \\
\hline \multirow{2}{*}{\multicolumn{4}{|c|}{$\begin{array}{l}\text { On the other hand, the smallest nanoplastic particle that can be } \\
\text { detected and quantified by this strategy will be determined by }\end{array}$}} & water & $2.23 \times 10^{8}$ & $2.00 \pm 0.07 \times 10^{8}$ & $13.1 \pm 0.4$ \\
\hline & & & & iver water & $2.15 \times 10^{8}$ & $2.12 \pm 0.07 \times 10^{8}$ & $13.2 \pm 0.2$ \\
\hline
\end{tabular}
the surface available for labelling and hence by its diameter and also by its degree of surface functionalization. By assuming a fully functionalized nanoplastic, the theoretical limit of detection of the proposed strategy is calculated as $135 \mathrm{~nm}$. This diameter corresponds to a nanoplastic containing the minimum available surface for labeling a number of AuNPs@gel able to produce a signal detectable from the background signal according to equation 2 . In any case, these results demonstrated the capability of the labelling strategy to detect and quantify plastics particles up to a size of $1000 \mathrm{~nm}$, covering then the upper size limit for the definition of a nanoplastic proposed by Gigault et $a l^{8}$.

Detection and quantification of nanoplastics in water samples. The feasibility of the proposed strategy was in three different matrices: tap water, river water and a drinking water. For that, a suspension of model PS22 nanoplastics of around 1 $\mathrm{x} 10^{12}$ NPTs $\mathrm{L}^{-1}$ was prepared in the three matrices listed above, a suspension of AuNPs@gel was spiked and the resulting mixture of conjugate PS22 nanoplastics- AuNPs@gel diluted and analyzed by SP-ICP-MS.

As it is shown in Figure 5, nanoplastics were well detected regardless of the matrix studied. Moreover, the signal due to conjugated nanoplastics could be well discriminated from the background, which lead to accurate quantifications (Table 4), showing that the proposed strategy can be successfully applied in drinking water, tap water and even in river water, where the presence of organic matter and other colloids could modify the behavior and physicochemical properties of nanoplastics, as it was pointed out elsewhere ${ }^{47}$.

On the other hand, no significant differences were observed on the Au mass per nanoplastics particle obtained when the experiments were conducted in tap water and river water (Table 4). In addition, these values were close to those obtained working in ultrapure water (Table 3). However, the Au mass per nanoplastic obtained in drinking water is significant lower ( $7.4 \mathrm{fg}$ vs 13.1 and $13.2 \mathrm{fg}$ ). This may be explained by differences in the quality parameters of the three matrices. For this purpose, $\mathrm{pH}$, conductivity and carbonate content were determined (Table S-1). In comparison with tap water and river water (which was collected from a pristine point), drinking water presented higher carbonate content and conductivity. The latter may have an influence on the labelling strategy by reducing the electrostatic interaction between the negative charge at the surface of nanoplastics, and the positive charge of AuNPs@gel. In any case, the determination of the nanoplastic number concentration was not hampered by a labelling with a lower number of AuNPs@gel.

Table 4. Nanoplastic number concentration obtained by SP-ICP-MS for a model PS nanoplastic suspension in different matrices

\begin{tabular}{llll}
\hline Water sample & $\begin{array}{l}\text { Theoretical } \\
\text { concentration, } \\
\text { NPTs L }^{-1}\end{array}$ & $\begin{array}{l}\text { Experimental } \\
\text { concentration, } \\
\text { NPTs L }^{-1}\end{array}$ & $\begin{array}{l}\text { Average } \\
\text { Au mass } \\
\text { per NPT, } \\
\text { fg }\end{array}$ \\
\hline $\begin{array}{l}\text { Drinking } \\
\text { water }\end{array}$ & $5.46 \times 10^{7}$ & $5.74 \pm 0.19 \times 10^{7}$ & $7.4 \pm 0.1$
\end{tabular}

However, the developed approach may not be directly applied in more complex matrices presenting negatively charged species like organic dissolved matter and/or other particles which may compete for the positively charged groups at the surface of the AuNP@gel. In this case, dedicated sample preparations steps, including matrix degradation and nanoplastics isolation must be developed.
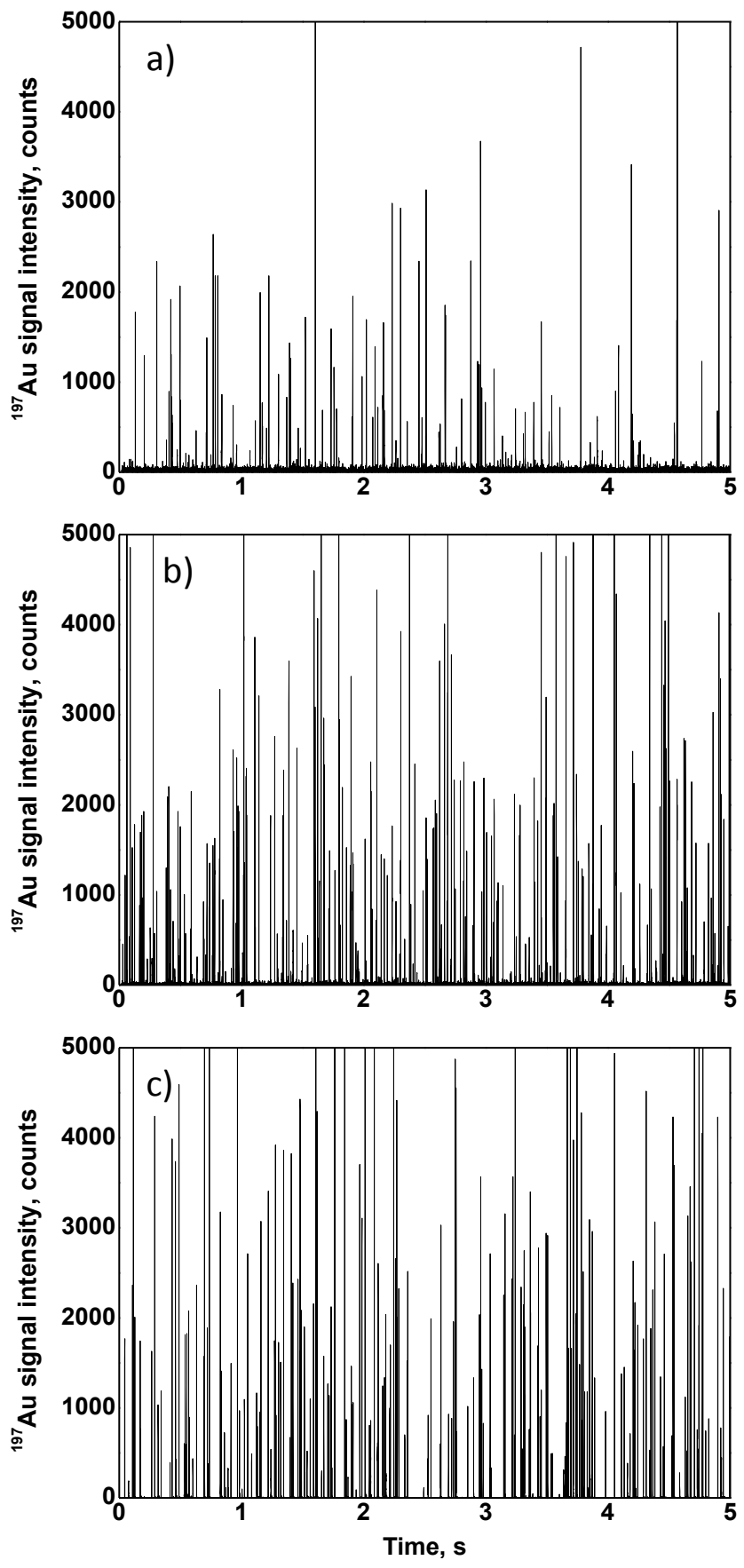

Figure 5. Time scans obtained by SP-ICP-MS for a suspension of PS22 model nanoplastics conjugated with AuNPs@gel in different matrices: a) drinking water, b) tap water, and c) river water. 


\section{CONCLUSIONS}

A novel analytical method for the detection and quantification of nanoplastics in aqueous media was developed. The strategy took advantage of the oxidation signature of ageing plastic debris, mimicked by carboxyl groups present at the surface of nanoplastic particles for their conjugation with functionalized positively charged AuNPs. These results showed that the Au signal generated by the conjugated nanoplastics allowed their counting in a particle-by-particle basis. This work demonstrated the suitability of SP-ICP-MS analysis after metal labelling to detect and determine nanoplastic number concentration of nanoplastics with sizes up to $1 \mu \mathrm{m}$ in different water samples. While the development of the analytical strategy was based on model studies and applications were demonstrated on synthetic samples, the proposed concept has a significant potential to become the basis of analysis of environmental (e.g., seawater, river water, waste water) samples containing nanoplastics with carbonyl groups due to oxidation processes. However, the study of more complex matrices and real environmental samples should imply additional nanoplastic isolation and/or preconcentration steps and hence further analytical development. Finally, by assuming a constant density of AuNPs@gel labelled per nanoplastic, this approach can eventually be applied to measure the surface available area and hence the size of isotropic nanoplastics. For anisotropic nanoplastics, closer to what is expected in real samples, information about available surface could be obtained.

\section{Supporting Information}

The Supporting Information is available free of charge on the ACS Publications website.

Supporting Table S1: Quality parameters of the three aqueous matrices studied. Supporting Figures S1-S4, showing the following: Size distribution obtained by SP-ICP-MS, of the AuNPs@gel used for nanoplastic labelling and UV-Vis spectra of AuNPs@gel suspension; SEM image and size distribution obtained for the 50nm AuNPs suspension; Loss of linear relationship between nanoplastic number concentration and number of peaks counted by SPICP-MS at number concentrations above $3.5 \times 10^{8} \mathrm{NPTs} \mathrm{L}^{-1}$; Time scans obtained by SP-ICP-MS after applying the labelling strategy to commercial PSL nanoplastic standards with nominal diameters of: a) $759 \mathrm{~nm}$, b) $990 \mathrm{~nm}$, and c) $3030 \mathrm{~nm}$.

\section{AUTHOR INFORMATION}

\section{Corresponding Author}

* Phone: +33540175037. E-mail: j.jimenez-lamana@univ-pau.fr

\section{Author Contributions}

The manuscript was written through contributions of all authors. / All authors have given approval to the final version of the manuscript.

\section{ACKNOWLEDGMENTS}

Authors thank Josep Sanchís from the Catalan Institute for Water Research (ICRA) in Girona, Catalonia, Spain for collecting the river sample. This research was carried under the framework of E2S UPPA supported by the "Investissements d'Avenir" French programme managed by ANR (ANR-16-IDEX-0002). This research was funded by the Aquitaine Region through the project AQUITRACES (n²0131206001-1301097)

\section{REFERENCES}

(1) Triebskorn, R.; Braunbeck, T.; Grummt, T.; Hanslik, L.; Huppertsberg, S.; Jekel, M.; Knepper, T. P.; Krais, S.; Müller, Y. K.; Pittroff, M.; Ruhl, A. S.; Schmieg, H.; Schür, C.; Strobel, C.; Wagner, M.; Zumbülte, N.; Köhler, H. R. Relevance of Nano- and Microplastics for Freshwater Ecosystems: A Critical Review. TrAC - Trends Anal. Chem. 2019, 110, 375-392. https://doi.org/10.1016/j.trac.2018.11.023.

(2) Andrady, A. L. Microplastics in the Marine Environment. Mar Pollut. Bull. 2011, 62 (8), 1596-1605. https://doi.org/10.1016/j.marpolbul.2011.05.030.

(3) Gigault, J.; Pedrono, B.; Maxit, B.; Ter Halle, A. Marine Plastic Litter: The Unanalyzed Nano-Fraction. Environ. Sci. Nano 2016, 3 (2), 346-350. https://doi.org/10.1039/c6en00008h.

(4) Jahnke, A.; Arp, H. P. H.; Escher, B. I.; Gewert, B.; Gorokhova E.; Kühnel, D.; Ogonowski, M.; Potthoff, A.; Rummel, C.; Schmitt-Jansen, M.; Toorman, E.; MacLeod, M. Reducing Uncertainty and Confronting Ignorance about the Possible Impacts of Weathering Plastic in the Marine Environment. Environ. Sci. Technol. Lett. 2017, 4 (3), 85-90. https://doi.org/10.1021/acs.estlett.7b00008.

(5) Silva, A. B.; Bastos, A. S.; Justino, C. I. L.; da Costa, J. P.; Duarte, A. C.; Rocha-Santos, T. A. P. Microplastics in the Environment: Challenges in Analytical Chemistry - A Review. Anal. Chim. Acta 2018, 1017, 1-19. https://doi.org/10.1016/j.aca.2018.02.043.

(6) Koelmans, A. A. Proxies for Nanoplastic. Nat. Nanotechnol. 2019, 14 (April), 307-308.

(7) Editorial. Nanoplastic Should Be Better Understood. Nat. $\begin{array}{llll}\text { Nanotechnol. } & \text { 2019, } & 14 & \text { (April), }\end{array}$ https://doi.org/10.1038/s41565-019-0437-7.

(8) Gigault, J.; Halle, A. ter; Baudrimont, M.; Pascal, P. Y.; Gauffre, F.; Phi, T. L.; El Hadri, H.; Grassl, B.; Reynaud, S. Current Opinion: What Is a Nanoplastic? Environ. Pollut. 2018, 235, 1030-1034. https://doi.org/10.1016/j.envpol.2018.01.024.

(9) Besseling, E.; Redondo-Hasselerharm, P.; Foekema, E. M.; Koelmans, A. A. Quantifying Ecological Risks of Aquatic Micro- and Nanoplastic. Crit. Rev. Environ. Sci. Technol. 2019, 49 (1), 32-80. https://doi.org/10.1080/10643389.2018.1531688.

(10) Science Advice for Policy by European Academies (SAPEA). A Scientific Perspective on Microplastics in Nature and Society | SAPEA; 2019. https://doi.org/10.26356/microplastics.

(11) Peng, L.; Fu, D.; Qi, H.; Lan, C. Q.; Yu, H.; Ge, C. Micro- and Nano-Plastics in Marine Environment: Source, Distribution and Threats — A Review. Sci. Total Environ. 2020, 698, 134254. https://doi.org/10.1016/j.scitotenv.2019.134254.

(12) Ter Halle, A.; Jeanneau, L.; Martignac, M.; Jardé, E.; Pedrono, B.; Brach, L.; Gigault, J. Nanoplastic in the North Atlantic Subtropical Gyre. Environ. Sci. Technol. 2017, 51 (23), 1368913697. https://doi.org/10.1021/acs.est.7b03667.

(13) Alexy, P.; Anklam, E.; Emans, T.; Furfari, A.; Galgani, F.; Hanke, G.; Koelmans, A.; Pant, R.; Saveyn, H.; Sokull Kluettgen, B. Managing the Analytical Challenges Related to Micro- and Nanoplastics in the Environment and Food: Filling the Knowledge Gaps. Food Addit. Contam. - Part A Chem. Anal. Control. Expo. Risk Assess. 2020, 37 (1), 1-10. https://doi.org/10.1080/19440049.2019.1673905.

(14) Oliveira, M.; Almeida, M. The Why and How of Micro(Nano)Plastic Research. TrAC - Trends Anal. Chem. 2019, 114, 196-201. https://doi.org/10.1016/j.trac.2019.02.023.

(15) Schwaferts, C.; Niessner, R.; Elsner, M.; Ivleva, N. P. Methods for the Analysis of Submicrometer- and Nanoplastic Particles in the Environment. TrAC - Trends Anal. Chem. 2019, 112, 52-65. https://doi.org/10.1016/j.trac.2018.12.014.

(16) Ekvall, M. T.; Lundqvist, M.; Kelpsiene, E.; Šileikis, E.; Gunnarsson, S. B.; Cedervall, T. Nanoplastics Formed during the Mechanical Breakdown of Daily-Use Polystyrene Products. Nanoscale Adv. 2019, 1 (3), 1055-1061. https://doi.org/10.1039/c8na00210j.

(17) Lambert, S.; Wagner, M. Characterisation of Nanoplastics during the Degradation of Polystyrene. Chemosphere 2016, 145, 265-268. https://doi.org/10.1016/j.chemosphere.2015.11.078.

(18) Hernandez, L. M.; Xu, E. G.; Larsson, H. C. E.; Tahara, R.; Maisuria, V. B.; Tufenkji, N. Plastic Teabags Release Billions of Microparticles and Nanoparticles into Tea. Environ. Sci. 
Technol. 2019, $\quad 53 \quad$ (21), 12300-12310. https://doi.org/10.1021/acs.est.9b02540.

(19) Hernandez, L. M.; Yousefi, N.; Tufenkji, N. Are There Nanoplastics in Your Personal Care Products? Environ. Sci. Technol. Lett. 2017, 4 (7), 280-285. https://doi.org/10.1021/acs.estlett.7b00187.

(20) Chen, Q.; Gundlach, M.; Yang, S.; Jiang, J.; Velki, M.; Yin, D.; Hollert, H. Quantitative Investigation of the Mechanisms of Microplastics and Nanoplastics toward Zebrafish Larvae Locomotor Activity. Sci. Total Environ. 2017, 584-585, 1022 1031. https://doi.org/10.1016/j.scitotenv.2017.01.156.

(21) Gniadek, M.; Dąbrowska, A. The Marine Nano- and Microplastics Characterisation by SEM-EDX: The Potential of the Method in Comparison with Various Physical and Chemical Approaches. Marine Pollution Bulletin. 2019, pp 210-216. https://doi.org/10.1016/j.marpolbul.2019.07.067.

(22) Brun, N. R.; Beenakker, M. M. T.; Hunting, E. R.; Ebert, D.; Vijver, M. G. Brood Pouch-Mediated Polystyrene Nanoparticle Uptake during Daphnia Magna Embryogenesis. Nanotoxicology 2017, $11 \quad$ (8), 1059-1069. https://doi.org/10.1080/17435390.2017.1391344.

(23) Rist, S.; Baun, A.; Hartmann, N. B. Ingestion of Micro- and Nanoplastics in Daphnia Magna - Quantification of Body Burdens and Assessment of Feeding Rates and Reproduction. Environ. Pollut. 2017, 228, 398-407. https://doi.org/10.1016/j.envpol.2017.05.048.

(24) Gigault, J.; El Hadri, H.; Reynaud, S.; Deniau, E.; Grassl, B. Asymmetrical Flow Field Flow Fractionation Methods to Characterize Submicron Particles: Application to Carbon-Based Aggregates and Nanoplastics. Anal. Bioanal. Chem. 2017, 409 (29), 6761-6769. https://doi.org/10.1007/s00216-017-0629-7.

(25) Correia, M.; Loeschner, K. Detection of Nanoplastics in Food by Asymmetric Flow Field-Flow Fractionation Coupled to Multi-Angle Light Scattering: Possibilities, Challenges and Analytical Limitations. Analytical and Bioanalytical Chemistry. 2018, pp 5603-5615. https://doi.org/10.1007/s00216-018-09198.

(26) Abdolahpur Monikh, F.; Grundschober, N.; Romeijn, S.; Arenas-Lago, D.; Vijver, M. G.; Jiskoot, W.; Peijnenburg, W. J. G. M. Development of Methods for Extraction and Analytical Characterization of Carbon-Based Nanomaterials (Nanoplastics and Carbon Nanotubes) in Biological and Environmental Matrices by Asymmetrical Flow Field-Flow Fractionation. Environ. Pollut. 2019, 255, 113304 https://doi.org/10.1016/j.envpol.2019.113304.

(27) da Costa, J. P.; Santos, P. S. M.; Duarte, A. C.; Rocha-Santos, T. (Nano)Plastics in the Environment - Sources, Fates and Effects. Sci. Total Environ. 2016, 566-567, 15-26. https://doi.org/10.1016/j.scitotenv.2016.05.041.

(28) Mintenig, S. M.; Bäuerlein, P. S.; Koelmans, A. A.; Dekker, S. C.; Van Wezel, A. P. Closing the Gap between Small and Smaller: Towards a Framework to Analyse Nano- and Microplastics in Aqueous Environmental Samples. Environ. Sci. Nano $\quad \mathbf{2 0 1 8}, \quad 5 \quad$ (7), 1640-1649. https://doi.org/10.1039/c8en00186c.

(29) Zhou, X. X.; Hao, L. T.; Wang, H. Y. Z.; Li, Y. J.; Liu, J. F. Cloud-Point Extraction Combined with Thermal Degradation for Nanoplastic Analysis Using Pyrolysis Gas ChromatographyMass Spectrometry. Anal. Chem. 2019, 91 (3), 1785-1790. https://doi.org/10.1021/acs.analchem.8b04729.

(30) Nguyen, B.; Claveau-Mallet, D.; Hernandez, L. M.; Xu, E. G.; Farner, J. M.; Tufenkji, N. Separation and Analysis of Microplastics and Nanoplastics in Complex Environmental Samples. Acc. Chem. Res. 2019, 52 (4), 858-866. https://doi.org/10.1021/acs.accounts.8b00602.

(31) Lin, Y.; Huang, X.; Liu, Q.; Lin, Z.; Jiang, G. Thermal Fragmentation Enhanced Identification and Quantification of Polystyrene Micro/Nanoplastics in Complex Media. Talanta 2020, 208 (October 2019), 120478. https://doi.org/10.1016/j.talanta.2019.120478.

(32) Schirinzi, G. F.; Llorca, M.; Seró, R.; Moyano, E.; Barceló, D.; Abad, E.; Farré, M. Trace Analysis of Polystyrene Microplastics in Natural Waters. Chemosphere 2019, 236. https://doi.org/10.1016/j.chemosphere.2019.07.052. and Toxic Chemicals in the Ocean. Environ. Sci. Technol. 2012, 46 (22), 12302-12315. https://doi.org/10.1021/es3027105.

Strungaru, S. A.; Jijie, R.; Nicoara, M.; Plavan, G.; Faggio, C. Micro- (Nano) Plastics in Freshwater Ecosystems: Abundance, Toxicological Impact and Quantification Methodology. TrAC Trends Anal. Chem. 2019, 110, 116-128. https://doi.org/10.1016/j.trac.2018.10.025.

(35) El Hadri, H.; Gigault, J.; Maxit, B.; Grassl, B.; Reynaud, S. Nanoplastic from Mechanically Degraded Primary and Secondary Microplastics for Environmental Assessments. $\begin{array}{llll}\text { NanoImpact } & \mathbf{2 0 2 0}, & 17, & 100206\end{array}$ https://doi.org/10.1016/j.impact.2019.100206.

(36) Laborda, F.; Bolea, E.; Jiménez-Lamana, J. Single Particle Inductively Coupled Plasma Mass Spectrometry: A Powerful Tool for Nanoanalysis. Anal. Chem. 2014, 86 (5), 2270-2278. https://doi.org/10.1021/ac402980q.

(37) Pessoni, L.; Veclin, C.; El Hadri, H.; Cugnet, C.; Davranche, M.; Pierson-Wickmann, A. C.; Gigault, J.; Grassl, B.; Reynaud, S. Soap- and Metal-Free Polystyrene Latex Particles as a Nanoplastic Model. Environ. Sci. Nano 2019, 6 (7), 2253-2258. https://doi.org/10.1039/c9en00384c.

(38) Pace, H. E.; Rogers, N. J.; Jarolimek, C.; Coleman, V. A.; Higgins, C. P.; Ranville, J. F. Determining Transport Efficiency for the Purpose of Counting and Sizing Nanoparticles via Single Particle Inductively Coupled Plasma Mass Spectrometry (Vol 83, Pg 9361, 2011). Anal. Chem. 2011, 83 (10), 9361-9369. https://doi.org/10.1021/ac300942m.

(39) Soulé, S.; Bulteau, A. L.; Faucher, S.; Haye, B.; Aimé, C.; Allouche, J.; Dupin, J. C.; Lespes, G.; Coradin, T.; Martinez, H. Design and Cellular Fate of Bioinspired $\mathrm{Au}-\mathrm{Ag}$ Nanoshells@Hybrid Silica Nanoparticles. Langmuir 2016, 32 (39), https://doi.org/10.1021/acs.langmuir.6b02810.

(40) Amendola, V.; Pilot, R.; Frasconi, M. Surface Plasmon Resonance in Gold Nanoparticles : A Review. J. Phys. Condens. Matter 2017, 29, 203002.

(41) Torrent, L.; Laborda, F.; Marguí, E.; Hidalgo, M.; Iglesias, M. Combination of Cloud Point Extraction with Single Particle Inductively Coupled Plasma Mass Spectrometry to Characterize Silver Nanoparticles in Soil Leachates. Anal. Bioanal. Chem. 2019, 411 (20), 5317-5329. https://doi.org/10.1007/s00216-01901914-y.

(42) Liu, J.; Murphy, K. E.; Winchester, M. R.; Hackley, V. A. Overcoming Challenges in Single Particle Inductively Coupled Plasma Mass Spectrometry Measurement of Silver Nanoparticles. Anal. Bioanal. Chem. 2017, 409, 6027-6039. https://doi.org/10.1007/s00216-017-0530-4.

(43) Jiménez-Lamana, J.; Abad-Álvaro, I.; Katarzyna, B.; Laborda, F.; Szpunar, J.; Lobinski, R. Detection and Characterization of Biogenic Selenium Nanoparticles in Selenium-Rich Yeast by Single Particle ICPMS. J. Anal. At. Spectrom. 2018, 33, 452460. https://doi.org/10.1039/C7JA00378A.

(44) Kińska, K.; Jiménez-Lamana, J.; Kowalska, J.; KrasnodębskaOstręga, B.; Szpunar, J. Study of the Uptake and Bioaccumulation of Palladium Nanoparticles by Sinapis Alba Using Single Particle ICP-MS. Sci. Total Environ. 2018, 615, 1078-1085. https://doi.org/10.1016/j.scitotenv.2017.09.203.

(45) Laborda, F.; Gimenez-Ingalaturre, A. C.; Bolea, E.; Castillo, J. R. Single Particle Inductively Coupled Plasma Mass Spectrometry as Screening Tool for Detection of Particles. Spectrochim. Acta - Part B At. Spectrosc. 2019, 159 (January), 105654. https://doi.org/10.1016/j.sab.2019.105654

(46) Wojcieszek, J.; Jimenez-Lamana, J.; Bierla, K.; Asztemborska, M.; Ruzik, L.; Jarosz, M.; Szpunar, J. Elucidation of the Fate of Zinc in Model Plants Using Single Particle ICP-MS and ESI Tandem MS. J. Anal. At. Spectrom. 2019, 34, 683-693. https://doi.org/10.1039/C8JA00390D.

(47) Oriekhova, O.; Stoll, S. Heteroaggregation of Nanoplastic Particles in the Presence of Inorganic Colloids and Natural Organic Matter. Environ. Sci. Nano 2018, 5 (3), 792-799. https://doi.org/10.1039/c7en01119a. 
"For Table of Contents Only"
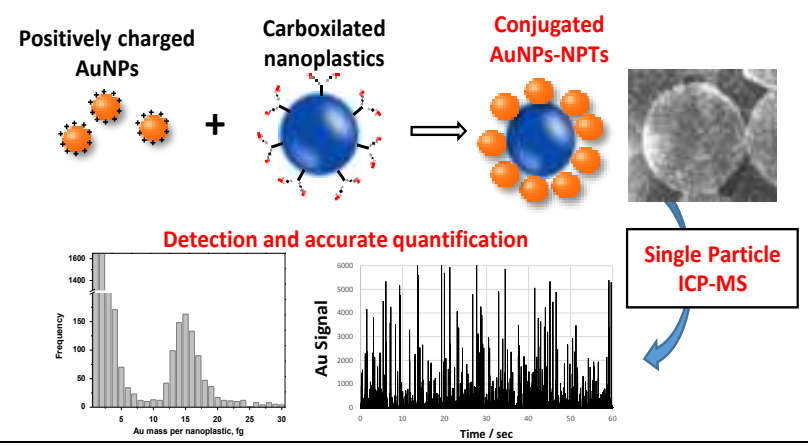